\title{
Heterogeneity of Progenitor Cell Populations and their Therapeutic Implications
}

Elizabeth R Zielins ${ }^{1}$, Anna Luan'1, Ruth Tevlin ${ }^{1}$, Victor W Wong ${ }^{2}$, Arash Momeni', Michael T Longaker ${ }^{1}$ and Derrick C Wan ${ }^{1 *}$

${ }^{1}$ Hagey Laboratory for Pediatric Regenerative Medicine, Department of Surgery, Division of Plastic Surgery, Stanford University School of Medicine, Stanford, California, USA

${ }^{2}$ Department of Plastic and Reconstructive Surgery, Johns Hopkins Hospital, Baltimore, Maryland, USA

\begin{abstract}
Stem cell populations throughout the human body are known to be heterogenous, though the extent of their heterogeneity and how this can be harnessed to provide more effective tissue regeneration remains questionable. Herein we describe not only the existence of heterogenous progenitor populations in a variety of tissues, but also currently utilized means for isolation of them, and the particular promise held in the ability to isolate progenitor cell populations from adipose-derived stromal cells.
\end{abstract}

Keywords: Progenitor cell; Stem cell; Adipose-derived stem cell; Subpopulation

\section{Introduction}

The desire to recapitulate lost or damaged tissues/organs utilizing the body's own cells forms the basis of the field of regenerative medicine. Since the discovery of the mouse Hematopoietic Stem Cell (HSC) in 1988, stem cell populations from a myriad of other tissues have been isolated, with much progress being made in their characterization [1]. Yet, while initially assumed to be homogenous, progenitor cell populations have since been discovered to possess a great amount of heterogeneity [2]. Though multipotent by nature, some progenitor cells seem to have a predisposition towards becoming cells of one lineage as opposed to another. This is particularly evident when one considers bone marrow-derived mesenchymal stem cells (MSCs) and Adipose Derived Stromal Cells (ASCs), though this predilection can be seen in many other tissue-specific progenitor cell populations, such as those residing in cardiac tissue and skin.

Technological advances enabling the isolation and characterization of these more specialized progenitors from larger stem cell pools hinge primarily on the use of flow cytometry and transcriptome analysis such as next generation sequencing (NGS). Research in this area continues to be of importance, as we aim to harness the potential of various progenitor cell populations for regenerative medicine. As such, in this review we provide an overview of some of the known heterogenous progenitor cell populations present throughout the body, with a focus on ASCs. Furthermore, the clinical implications of their heterogeneity will be discussed.

\section{Diversity of Progenitor Cell Populations}

In a constantly changing world, heterogeneity imparts a survival advantage for a species as a whole. However, on an individual level, diversity can be just as important. Tissues/organs throughout the body respond to a variety of external stimuli, and this ability to adapt may be reflected in the heterogeneity of resident progenitor cells. Well documented examples of this include progenitor cells found in cardiac, skin, bone, and adipose tissues.

The origin of cardiogenic cells and their roles in organ development have fascinated biologists for over a century, spawning intense interest and controversy regarding the therapeutic potential of cardiac stem cells. Currently, three fundamental principles underlie the contemporary state of knowledge regarding cardiac progenitor cells: (1) Multi-potent
Cardiac Progenitor Cells (CPCs) exist in the embryonic mammalian heart, having been first described in 2006; (2) a limited number of new cardiomyocytes are created in postnatal mammals; and (3) with the exception of neonatal mice, newts, and zebrafish, few organisms can regenerate damaged myocardium [3-11]. By tracking hematopoietic and cardiac embryonic development, Kouskoff et al. found that CPCs may arise from a mesodermal precursor subpopulation expressing fetal liver kinase-1 [12,13]. CPCs have also been isolated from postnatal mammalian (including human) myocardium, and they have the capacity for self-renewal, proliferation, and differentiation into cardiomyocytes, smooth muscle, and endothelial cells [3,14-16] More recently, epicardial derived progenitor cells have been described with the ability to contribute to adventitial and interstitial fibroblasts, and to cardiomyocytes in the developing heart $[17,18]$. Similarly, cells originating from the embryonic endocardial cushions serve as progenitor cells for the cardiac valves [19-21]. Collectively, the diversity of progenitor cells identified which may contribute to cardiogenesis and homeostasis underscores the complexity of this organ and undoubtedly has implications for regenerative strategies aimed at cardiac tissue repair.

Like cardiac tissue, heterogeneity of progenitor cells can also be found in the skin. Two populations of epidermal progenitors residing in the basal layer have been shown to be responsible for normal cell turnover: a pool of progenitor cells that both self-renew and contribute to the formation of the overlying layers, and a stem cell population contributing to both overall epidermal maintenance and the regenerative response to injury [22]. Within the dermis, the heterogeneity of fibroblast populations also has been of particular interest, precisely due to the dermal response to wounding. Deep

*Corresponding author: Derrick C Wan, Hagey Laboratory for Pediatric Regenerative Medicine, Stanford University School of Medicine, 257 Campus Drive, Stanford, CA 94305-5148, USA, Tel: (650) 736-1707; Fax: (650) 736-1705 E-mail: dwan@stanford.edu

Received August 04, 2014; Accepted December 15, 2014; Published December 17,2014

Citation: Zielins ER, Luan A, Tevlin R, Wong VW, Momeni A, et al. (2014) Heterogeneity of Progenitor Cell Populations and their Therapeutic Implications. Stem Cell Res Ther 4: 254. doi:10.4172/2157-7633.1000254

Copyright: (c) 2014 Zielins ER, et al. This is an open-access article distributed under the terms of the Creative Commons Attribution License, which permits unrestricted use, distribution, and reproduction in any medium, provided the original author and source are credited. 
dermal fibroblasts, in contrast to more superficial fibroblasts, have been implicated in hypertrophic scarring, and lineage tracing experiments have shown that the origin of fibroblasts from the upper and lower dermis are embryonically distinct [23]. Furthermore, work from our own laboratory has revealed that different fibroblast populations comprise the dermis in different areas of the body.

Similar to skin, bone undergoes continual turnover. Interestingly though, bone may also heal without a scar following injury. Recently, emphasis has been placed on the isolation and characterization of the progenitor cells allowing for osseous regeneration and homeostasis. Lineage tracing experiments utilizing transgenic mice have shown differential contributions of mesenchymal stem and progenitor cells to the developing bone throughout the murine lifespan, though the developmental origin and hierarchical relationships between these populations remain largely unknown [24]. Our laboratory has additionally demonstrated that bone progenitor cell populations may be anatomically distinct, showing that calvarial bone osteoblasts of neural crest origin have superior potential for osteogenic differentiation compared to osteoblasts from paraxial mesoderm-derived parietal bone. This superiority extends to in vivo osseous healing of calvarial defects, which Quarto et al. linked to enhance endogenous canonical Wnt signaling in frontal bone as compared to parietal [25].

While the heart, skin, and bone all possess diverse progenitor cell populations contributing to tissue-specific homeostasis and regeneration/repair, adipose tissue contains one of the more wellstudied and easily accessible pools of cells with multipotent capacity [26]. Within the Stromal Vascular Fracture (SVF) of fat reside adipose-derived stromal cells (ASCs), fibroblasts, endothelial cells, erythrocytes, lymphocytes, monocytes, and pericytes. Importantly, ASCs are multipotent cells with the capacity to differentiate into multiple tissue types including fat, bone, cartilage, and muscle [27-31]. Interestingly, ASCs have also been reported to potentially differentiate along angiogenic [32,33], epithelial [34,35], neurogenic [27,36-38], and hepatic $[39,40]$ pathways. Increasingly, ASCs have thus become exciting clinical targets for regenerative medicine due to the advantages of fat compared to bone marrow as a source of progenitor cells. Furthermore, increasing evidence is emerging that ASCs themselves are heterogeneous, with varying differentiation capacities for the different lineages. This carries important implications for therapeutic applications, where enrichment for particular subpopulations may increase potency and therefore efficacy.

\section{Identification of Progenitor Cell Populations}

The identification and isolation of populations of progenitor cells with unique properties is facilitated by several technologies. Most are dependent on the use of flow cytometry, specifically fluorescenceactivated cell sorting (FACS), for isolation and analysis at the singlecell level. FACS alone has permitted reliable, reproducible isolation of certain cell populations based on defined surface marker profiles. For example, The International Society for Cellular Therapy (ISCT) has defined mesenchymal stem cells (MSCs) as being positive for the expression of CD90 (Thy-1), CD73 (NT5E), and CD105 (endoglin), and negative for expression of HLA-DR, CD11b/CD14, CD19/CD79a, $\mathrm{CD} 34$, and CD45 [41]. It should be noted that while ASCs are technically considered MSCs, variable expression of CD34 differentiates them from BM-MSCs [42].

As of yet there is no single cell surface marker that can be used to identify MSCs, posing a challenge to the large-scale reproducibility of experiments [43]. CD133 (Prominin-1) and CD326 (EpCAM) have been implicated as "stem cell markers", though primarily in the context of HSCs and cancer stem cells, and embryonic and hepatic stem cells, respectively $[44,45]$. However, research has shown that even these markers are not as specific as once thought. CD133 has been found to be present on central nervous system cancer cells regardless of stem/ progenitor cell properties [46]. Yet, aside from being a challenge to stem cell biologists, the lack of a unifying surface marker hints at the heterogeneity of an otherwise seemingly homogenous cell population. To that end, techniques employing broad-scope analysis at both the cell surface marker and transcriptional levels have been developed, with the hope of further defining progenitor cell subpopulations.

\section{Lyoplates}

Commercially known as "lyoplates," screening panels utilizing lyophilized antibodies provide a cost-effective, standardizable means to analyze a cell type for the expression of multiple cell surface markers [47]. Utilizing fluorescently-conjugated secondary antibodies, these plates may be analyzed visually (using the appropriate microscopy and image analysis techniques) or with FACS. In addition to the aforementioned practical benefits, lyoplate-based FACS analysis may offer superior discrimination between surface markers compared to conventional multicolor flow cytometry [48]. With that in mind, lyoplates are currently being used in the search for progenitor cell subpopulations. Baer et al. utilized them to comprehensively describe the immunophenotype of ASCs in culture; their findings correlated with previous studies that noted two subpopulations of ASCs defined by CD34 expression [49]. The authors commented that the CD34population of ASCs had been previously described as being more adipogenic and osteogenic than the $\mathrm{CD} 34^{+}$population, which had been shown to be more proliferative. Interestingly, Baer et al. found patientspecific variation in expression of 49 of the 242 antigens assayed using lyoplates [49]. Ong et al. also employed lyoplates to probe differences between ASC subpopulations, focusing on the variation between cells harvested from subcutaneous versus visceral fat. Though the lyoplates were analyzed using fluorescence microscopy as opposed to FACS, they successfully identified differential expression of two cell surface markers between the two fat depots [50].

\section{Single-cell analysis}

In contrast to the large-scale surface marker screening offered by lyoplates, progenitor cell populations may be alternatively defined using large-scale intracellular screening techniques. Microfluidic technologies have proved particularly helpful in this pursuit, as they enable the use of very low volumes of reagents/samples on the order of nano- to picoliters [51]. Single cell microfluidic technologies permit high-resolution interrogation of the transcriptional profiles of individual cells when used in conjunction with either quantitative polymerase chain reactions (qPCR), microarrays, or, most recently, RNA sequencing. Glotzbach et al. utilized single cell microfluidicbased qPCR to characterize subpopulations within a group of what had been previously assumed to be a homogenous pool of hematopoietic stem cells [52]. Similarly, Levi et al. identified several putatively proosteogenic surface markers using transcriptional profiling of 48 genes at the single cell level, and confirmed the in vitro and in vivo proosteogenic potential of an ASC subpopulation characterized by early expression of one of those markers, CD105 [53].

\section{Known Progenitor Cell Subpopulations and Their Therapeutic Implications}

Of the various diverse progenitor cell populations we have 


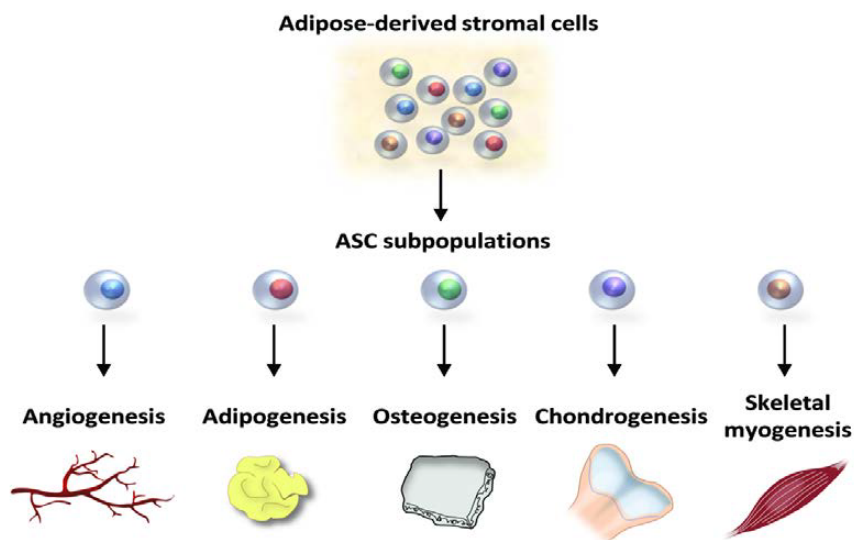

Figure 1: Schematic of heterogeneous ASCs showing potential subpopulations with enhanced vasculogenic, adipogenic, osteogenic, chondrogenic, and myogenic potential for regenerative strategies.

described, those present among ASCs offer the most exciting therapeutic implications. As previously mentioned, the multi-lineage potential of ASCs, combined with the relative ease of obtaining them, makes them attractive targets for the isolation of cell subpopulations for use in the clinical setting. The range of applications for ASCs predisposed to differentiate into one lineage as opposed to another is broad, as vasculogenic, adipogenic, osteogenic, chondrogenic, and myogenic progenitor cell populations have all been putatively identified (Figure 1).

\section{Vasculogenic}

Sharing many similarities with pericytes and themselves found in a perivascular niche, it is not surprising that ASCs should have provasculogenic potential $[54,55]$. Studies have demonstrated their promise for clinical use, such as Zografou et al's experiments demonstrating that autologous ASCs improve diabetic skin graft survival via direct contributions to the development of new blood vessels, in addition to their pro-angiogenic paracrine effects [56]. Though there in vitro and in vivo angio- and vasculogenic properties have yet to be studied, pericyte and endothelial progenitor populations within ASCs are characterized primarily by varying expression patterns of CD146, CD34, and CD31 [57]. SSEA-4, a marker initially thought to be specific to embryonic stem cells, has additionally been shown to identify a pro-vasculogenic and pro-adipogenic subpopulation of ASCs [58,59]. Isolation of ASC subpopulations based on these markers may facilitate strategies aimed at accelerating tissue regeneration through enhanced vascularity.

\section{Adipogenic}

Like angiogenic progenitor cell populations, adipogenic subpopulations of ASCs are of particular clinical interest given their potential for use in cell-assisted lipotransfer or, uniquely, for the creation of de novo fat. Li et al. artificially divided SVF into four subpopulations based on surface marker expression: an endothelial progenitor population, a circulating endothelial progenitor cell-like population, pericytes, and preadipocytes [60]. While all subpopulations demonstrated multipotency, the preadipocyte population, defined as $\mathrm{CD} 34^{+} \mathrm{CD} 31^{-}$and comprising the majority of cells in SVF, had the highest adipogenic potential. Interestingly, over 90 percent of the cells of this progenitor population were also $\mathrm{CD}^{+} 0^{+}$[60]. Similar to the differences seen in the osteogenic potential of neural crest vs. mesoderm-derived calvarial bones, the developmental origin of ASCs may contribute to their adipogenic ability. Sowa et al. found that, albeit small, the subpopulation of ASCs derived from the neural crest is phenotypically unique from non-neural crest derived ASCs, and restricted primarily to adipogenic differentiation [61].

\section{Osteogenic}

Known to possess subpopulations with enhanced bone-forming capabilities, researchers have identified several markers that may characterize pro-osteogenic ASC subpopulations. Our lab has identified three such surface markers, each facilitating isolation of progenitor cells with superior in vitro and in vivo osteogenic potential: CD105 $5^{\text {low }}$, CD90 (Thy-1) $)^{\text {high }}$, and bone morphogenetic protein receptor type-IB (BMPR-IB)+ all characterize pro-osteogenic ASCs $[53,62,63]$. Rada et al. also found CD29 and STRO-1 to characterize two separate highly-osteogenic ASC populations, with STRO-1+ $1^{+}$ASCs facilitating superior bone formation [64]. Interestingly, James et al. have also described the use of perivascular stem cells, isolated via FACS sorting, in experimental bone tissue engineering applications [65]. In addition to the previously-mentioned SSEA-4, the presence of surface marker p75 has been demonstrated as identifying a pro-osteogenic population of ASCs $[59,66]$. As progenitor cell populations with greater osteogenic potential continue to be defined, they can be incorporated into current therapies used in surgical reconstruction of deficient bone.

\section{Chondrogenic}

Articular cartilage is a relatively avascular tissue with low cellularity. Acute trauma, mechanical wear, and chronic disease may all leave cartilage unable to function appropriately as a smooth, load-bearing articular surface. Cartilage is particularly ineffective in being able to repair itself, and damaged cartilage contributes to further progression of disease in a vicious cycle. Thus, cartilage repair is an important potential application of cell-based regenerative medicine.

The chondrogenic potential of ASCs was relatively unexplored until the most recent decade. In 2007, Jo et al. found increased expression of CD10, CD13, CD44, CD49e, and CD73 to be associated with the chondrogenic process in isolated synovial cells [67]. In the following years, many surface markers have been implicated in identifying subpopulations of ASCs with enhanced chondrogenic capacity. The subpopulation of ASCs expressing CD105, a component of the TGFbeta receptor, has been shown by several groups to be more likely to differentiate into chondrocytes when compared to their CD105 counterparts $[66,68,69]$. Anderson et al. found that CD105 ${ }^{+}$and CD105 ASCs maintained distinct differentiation properties, with CD105 ASCs more prone to differentiate into adipocytes and osteocytes as opposed to chondrocytes [70].

Arufe et al. found that the $\mathrm{CD} 3^{+}$subpopulation of human synovial membrane MSCs expressed greater levels of Sox9 (a transcription factor implicated in chondrogenesis), COL2, and aggrecan [71]. Interestingly, this $\mathrm{CD}^{+} 3^{+}$subpopulation had a lower percentage of CD105 expression compared to other subpopulations. However, they also discovered a CD271 ${ }^{+}$ASC subpopulation with higher expression of Runx2, suggesting greater chondrogenic capacity, as well as a lower expression of $\mathrm{CD} 73$. In contrast to the $\mathrm{CD} 73^{+}$subpopulation, a high percentage of these $\mathrm{CD} 271^{+}$cells were also positive for CD105. Their findings suggest that there may be more complexity in the relationships between different surface markers in the differentiation capacity of subpopulations, rather than perhaps any one individual marker [72]. Other potential surface markers related to chondrogenesis that have been reported in the literature include CD166 [73-75], CD90 [76,77], CD29 [66], and CD39 [78]. 
Citation: Zielins ER, Luan A, Tevlin R, Wong VW, Momeni A, et al. (2014) Heterogeneity of Progenitor Cell Populations and their Therapeutic Implications. J Stem Cell Res Ther 4: 254. doi:10.4172/2157-7633.1000254

Page 4 of 6

In vitro, bone marrow-derived MSCs have been seeded onto a variety of different scaffolds resulting in cartilage-like production of extracellular matrix, histological structure, and immunohistochemical properties [79,80]. In vivo, alginate constructs with ASCs grown in chondrogenic media and then implanted subcutaneously in nude mice have also been shown to produce cartilage matrix molecules [81]. Interestingly, implanted induced ASC spheroids demonstrate a more hyaline-like cartilage phenotype and histological appearance when compared to their in vitro counterparts [82], emphasizing the importance of the in vivo microenvironment. Jiang et al. seeded $\mathrm{CD} 105^{+}$ASCs on a biodegradable scaffold and found that compared to similarly seeded and cultured $\mathrm{CD} 105^{-}$ASCs, the $\mathrm{CD} 105^{+}$constructs had a remarkably greater quantity of cartilage-like tissue, a more homogeneous histological structure with appropriate lacuna, and abundantly increased safranin-O and collagen II staining [69]. Further understanding of these ASC subpopulations will advance the field toward the goal of applying similar constructs to human disease.

\section{Myogenic}

Myogenic differentiation of ASCs occurs with low yield and reproducibility when compared to other pathways [83,84]. Although muscle markers (e.g. MyoD, Myf5, myogenin) are expressed by differentiating ASCs (whether murine or human) under the appropriate culture conditions, only a very low rate of fusion into myotubes has actually been observed in vitro $[27,28,85,86]$. Whether this observed low yield is due to a much smaller size of the subpopulation of ASCs with greater myogenic capacity, or if it is due to a uniformly low myogenic potential of all ASCs, is still unclear [84]. What is apparent, however, is that further studies should be done to help identify ASCs with potentially more myogenic capacity in order to improve yield, reproducibility, and applicability of ASCs to human muscular disease and injury.

Adult skeletal muscle is capable of self-repair by activating an otherwise-quiescent population of resident precursor cells, termed satellite cells. However, this capacity may be lost or depleted in disease, leading to progressive muscle degeneration. In the muscular dystrophies, the frequent requirement for regeneration exhausts the supply of satellite cells and the necrotic muscle is unable to be regenerated appropriately. In a mouse model of Duchenne muscular dystrophy (DMD), an X-linked disorder caused by a genetic mutation in the dystrophin gene, implantation of ASCs has been shown to restore dystrophin expression [87]. In vitro, ASCs cultured with human DMD myoblasts participate in myotube formation and induce dystrophin expression as well [88].

Studies have also examined the use of ASCs in models of muscle injury. After cardiotoxin-induced injury followed by injection of autologous ASCs, the anterior tibialis muscle of rabbits were heavier and had increased cross-sectional area [89]. Functionally, the treated muscles were able to exert greater maximal force; however, the clinical significance of the difference is yet unclear. In a murine model of ischemic limb injury, injection with human ASCs led to reduced muscle atrophy and increased vascularity, with evidence of myogenesis through the detection of human myogenin in the cells of treated mice [90]. Similar results have been found in other mouse models in which the femoral artery is removed [86]. Interestingly though, ASCs have been found to express low levels of M-cadherin and Caveolin-1, known cell-surface markers of muscle progenitor satellite cells [91]. Instead, characterization of ASCs based on expression of CD44 (mostly negative), CD45 (negative), CD73 (mostly positive), and CD90 (positive) identified cells with similar myogenic capacity to bone marrow-derived MSCs [92]. The identification and isolation of specific subpopulations of ASCs with enhanced myogenic capacity through additional markers will thus be critical in advancing potential clinical applications for these cells in muscle repair.

\section{Conclusions}

Though our understanding continues to grow on the existence of various progenitor cell subpopulations, much knowledge is still required before such cells may be implemented into clinical therapies. This is particularly true in the case of ASCs. While significant heterogeneity clearly exists among ASCs, development of technologies such as FACS, lyoplates, and single-cell analysis have allowed for definition and interrogation of distinct subpopulations. And with identification of ASC subgroups with enhanced vasculogenic, adipogenic, osteogenic, chondrogenic, or myogenic capacity, more effective regenerative strategies employing such fractions may be developed.

\section{References}

1. Spangrude GJ, Heimfeld S, Weissman IL (1988) Purification and characterization of mouse hematopoietic stem cells. Science 241: 58-62. [PubMed]

2. Wan DC, Longaker MT (2014) Fat or fiction: origins matter. Cell Metab 19 900-901. [PubMed]

3. Beltrami AP, Barlucchi L, Torella D, Baker M, Limana F, et al. (2003) Adult cardiac stem cells are multipotent and support myocardial regeneration. Cell 114: 763-776. [PubMed]

4. Garbern JC, Lee RT (2013) Cardiac stem cell therapy and the promise of heart regeneration. Cell Stem Cell 12: 689-698. [PubMed]

5. Wu SM, Fujiwara Y, Cibulsky SM, Clapham DE, Lien CL, et al. (2006) Developmental origin of a bipotential myocardial and smooth muscle cell precursor in the mammalian heart. Cell 127: 1137-1150. [PubMed]

6. Bergmann O, Bhardwaj RD, Bernard S, Zdunek S, Barnabé-Heider F, et al (2009) Evidence for cardiomyocyte renewal in humans. Science 324: 98-102. [PubMed]

7. Poss KD, Wilson LG, Keating MT (2002) Heart regeneration in zebrafish Science 298: 2188-2190. [PubMed]

8. Moretti A Caron L, Nakano A, Lam JT, Bernshausen A et al (2006) Multipotent embryonic isl1+ progenitor cells lead to cardiac, smooth muscle, and endothelial cell diversification. Cell 127: 1151-1165. [PubMed]

9. Oberpriller JO, Oberpriller JC (1974) Response of the adult newt ventricle to injury. J Exp Zool 187: 249-253. [PubMed]

10. Porrello ER, Mahmoud AI, Simpson E, Hill JA, Richardson JA, et al. (2011) Transient regenerative potential of the neonatal mouse heart. Science 331 : 1078-1080. [PubMed]

11. Jopling C, Sleep E, Raya M, Martí M, Raya A, et al. (2010) Zebrafish heart regeneration occurs by cardiomyocyte dedifferentiation and proliferation. Nature 464: 606-609. [PubMed]

12. Kouskoff V, Lacaud G, Schwantz S, Fehling HJ, Keller G (2005) Sequentia development of hematopoietic and cardiac mesoderm during embryonic stem cell differentiation. Proc Natl Acad Sci USA 102: 13170-13175. [PubMed]

13. Kattman SJ, Huber TL, Keller GM (2006) Multipotent flk-1+ cardiovascular progenitor cells give rise to the cardiomyocyte, endothelial, and vascular smooth muscle lineages. Dev Cell 11: 723-732. [PubMed]

14. Frati C, Savi M, Graiani G, Lagrasta C, Cavalli S, et al. (2011) Resident cardiac stem cells. Curr Pharm Des 17: 3252-3257. [PubMed]

15. Senyo SE, Steinhauser ML, Pizzimenti CL, Yang VK, Cai L, et al. (2013) Mammalian heart renewal by pre-existing cardiomyocytes. Nature 493: 433436. [PubMed]

16. Hsieh PC, Segers VF, Davis ME, MacGillivray C, Gannon J, et al. (2007) Evidence from a genetic fate-mapping study that stem cells refresh adult mammalian cardiomyocytes after injury. Nat Med 13: 970-974. [PubMed]

17. Gittenberger-de Groot AC, Vrancken Peeters MP, Mentink MM, Gourdie RG Poelmann RE (1998) Epicardium-derived cells contribute a novel population to 
Citation: Zielins ER, Luan A, Tevlin R, Wong VW, Momeni A, et al. (2014) Heterogeneity of Progenitor Cell Populations and their Therapeutic Implications. J Stem Cell Res Ther 4: 254. doi:10.4172/2157-7633.1000254

Page 5 of 6

the myocardial wall and the atrioventricular cushions. Circ Res 82: 1043-1052. [PubMed]

18. Wessels A, Pérez-Pomares JM (2004) The epicardium and epicardially derived cells (EPDCs) as cardiac stem cells. Anat Rec A Discov Mol Cell Evol Biol 276: 43-57. [PubMed]

19. Combs MD, Yutzey KE (2009) Heart valve development: regulatory networks in development and disease. Circ Res 105: 408-421. [PubMed]

20. Hinton RB, Yutzey KE (2011) Heart valve structure and function in development and disease. Annu Rev Physiol 73: 29-46. [PubMed]

21. Wu B, Baldwin HS, Zhou B (2013) Nfatc1 directs the endocardial progenito cells to make heart valve primordium. Trends Cardiovasc Med 23: 294-300. [PubMed]

22. Mascré G, Dekoninck S, Drogat B, Youssef KK, Broheé S, et al. (2012) Distinct contribution of stem and progenitor cells to epidermal maintenance. Nature 489: 257-262. [PubMed]

23. Driskell RR, Lichtenberger BM, Hoste E, Kretzschmar K, Simons BD, et al. (2013) Distinct fibroblast lineages determine dermal architecture in skin development and repair. Nature 504: 277-281. [PubMed]

24. Mizoguchi T, Pinho S, Ahmed J, Kunisaki Y, Hanoun M, et al. (2014) Osterix marks distinct waves of primitive and definitive stromal progenitors during bone marrow development. Dev Cell 29: 340-349. [PubMed]

25. Quarto N, Wan DC, Kwan MD, Panetta NJ, Li S, et al. (2010) Origin matters: differences in embryonic tissue origin and Wnt signaling determine the osteogenic potential and healing capacity of frontal and parietal calvarial bones. J Bone Miner Res 25: 1680-1694. [PubMed]

26. Zuk P (2013) Adipose-Derived Stem Cells in Tissue Regeneration: A Review ISRN Stem Cells 2013: 35.

27. Zuk PA, Zhu M, Ashjian P, De Ugarte DA, Huang Jl, et al. (2002) Human adipose tissue is a source of multipotent stem cells. Mol Biol Cell 13: 42794295. [PubMed]

28. Zuk PA, Zhu M, Mizuno H, Huang J, Futrell JW, et al. (2001) Multilineage cells from human adipose tissue: implications for cell-based therapies. Tissue Eng 7: 211-228. [PubMed]

29. Gimble J, Guilak F (2003) Adipose-derived adult stem cells: isolation characterization, and differentiation potential. Cytotherapy 5: 362-369. [PubMed]

30. Rodríguez LV, Alfonso Z, Zhang R, Leung J, Wu B, et al. (2006) Clonogenic multipotent stem cells in human adipose tissue differentiate into functional smooth muscle cells. Proc Natl Acad Sci USA 103: 12167-12172. [PubMed]

31. Pittenger MF, Mackay AM, Beck SC, Jaiswal RK, Douglas R, et al. (1999) Multilineage potential of adult human mesenchymal stem cells. Science 284 : 143-147. [PubMed]

32. Miranville A, Heeschen C, Sengenès C, Curat CA, Busse R, et al. (2004) Improvement of postnatal neovascularization by human adipose tissue-derived stem cells. Circulation 110: 349-355. [PubMed]

33. Planat-Benard V, Silvestre JS, Cousin B, André M, Nibbelink M, et al. (2004) Plasticity of human adipose lineage cells toward endothelial cells: physiological and therapeutic perspectives. Circulation 109: 656-663. [PubMed]

34. Brzoska M, Geiger H, Gauer S, Baer P (2005) Epithelial differentiation of human adipose tissue-derived adult stem cells. Biochem Biophys Res Commun 330: 142-150. [PubMed]

35. Baer PC, Brzoska M, Geiger H (2011) Epithelial differentiation of human adipose-derived stem cells. Methods Mol Biol 702: 289-298. [PubMed]

36. Safford KM, Hicok KC, Safford SD, Halvorsen YD, Wilkison WO, et al. (2002) Neurogenic differentiation of murine and human adipose-derived stromal cells. Biochem Biophys Res Commun 294: 371-379. [PubMed]

37. Safford KM, Safford SD, Gimble JM, Shetty AK, Rice HE (2004) Characterization of neuronal/glial differentiation of murine adipose-derived adult stromal cells. Exp Neurol 187: 319-328. [PubMed]

38. Ashiian PH, Elbarbary AS, Edmonds B, DeUgarte D, Zhu M, et al. (2003) In vitro differentiation of human processed lipoaspirate cells into early neural progenitors. Plast Reconstr Surg 111: 1922-1931. [PubMed]

39. Seo MJ, Suh SY, Bae YC, Jung JS (2005) Differentiation of human adipose stromal cells into hepatic lineage in vitro and in vivo. Biochem Biophys Res Commun 328: 258-264. [PubMed]

40. Ishikawa T, Banas A, Hagiwara K, Iwaguro H, Ochiya T (2010) Stem cells for hepatic regeneration: the role of adipose tissue derived mesenchymal stem cells. Curr Stem Cell Res Ther 5: 182-189. [PubMed]

41. Dominici M, Le Blanc K, Mueller I, Slaper-Cortenbach I, Marini F, et al. (2006) Minimal criteria for defining multipotent mesenchymal stromal cells. The International Society for Cellular Therapy position statement. Cytotherapy 8 : 315-317. [PubMed]

42. Pachón-Peña G, Yu G, Tucker A, Wu X, Vendrell J, et al. (2011) Stromal stem cells from adipose tissue and bone marrow of age-matched female donors display distinct immunophenotypic profiles. J Cell Physiol 226: 843-851. [PubMed]

43. Keating A (2012) Mesenchymal stromal cells: new directions. Cell Stem Cell 10: 709-716. [PubMed]

44. Adini A, Adini I, Ghosh K, Benny O, Pravda E, et al. (2013) The stem cell marker prominin-1/CD133 interacts with vascular endothelial growth factor and potentiates its action. Angiogenesis 16: 405-416. [PubMed]

45. Sundberg $M$, Jansson $L$, Ketolainen J, Pihlajamäki $H$, Suuronen $R$, et al. (2009) CD marker expression profiles of human embryonic stem cells and their neural derivatives, determined using flow-cytometric analysis; reveal a novel CD marker for exclusion of pluripotent stem cells. Stem Cell Res 2: 113-124. [PubMed]

46. Holmberg Olausson K, Maire CL, Haidar S, Ling J, Learner E, et al. (2014) Prominin-1 (CD133) defines both stem and non-stem cell populations in CNS development and gliomas. PLoS One 9: e106694. [PubMed]

47. O'Donnell EA, Ernst DN, Hingorani R (2013) Multiparameter flow cytometry: advances in high resolution analysis. Immune Netw 13: 43-54. [PubMed]

48. Villanova F, Di Meglio P, Inokuma M, Aghaeepour N, Perucha E, et al. (2013) Integration of lyoplate based flow cytometry and computational analysis for standardized immunological biomarker discovery. PLoS One 8: e65485. [PubMed]

49. Baer PC, Kuçi S, Krause M, Kuçi Z, Zielen S, et al. (2013) Comprehensive phenotypic characterization of human adipose-derived stromal/stem cells and their subsets by a high throughput technology. Stem Cells Dev 22: 330-339. [PubMed]

50. Ong WK, Tan CS, Chan KL, Goesantoso GG, Chan XH, et al. (2014) Identification of specific cell-surface markers of adipose-derived stem cells from subcutaneous and visceral fat depots. Stem Cell Reports 2: 171-179. [PubMed]

51. Ahn B, Wang Z, Archer DR, Lam WA (2014) Using microfluidics to investigate hematopoietic stem cell and microniche interactions at the single cell level. Methods Mol Biol 1185: 223-233. [PubMed]

52. Glotzbach JP (2011) An information theoretic, microfluidic-based single cell analysis permits identification of subpopulations among putatively homogeneous stem cells. PLoS One 6: e21211.

53. Levi B, Wan DC, Glotzbach JP, Hyun J, Januszyk M, et al. (2011) CD105 protein depletion enhances human adipose-derived stromal cell osteogenesis through reduction of transforming growth factor beta1 (TGF-beta1) signaling. $J$ Biol Chem 286: 39497-39509. [PubMed]

54. Traktuev DO, Merfeld-Clauss S, Li J, Kolonin M, Arap W, et al. (2008) A population of multipotent CD34-positive adipose stromal cells share pericyte and mesenchymal surface markers, reside in a periendothelial location, and stabilize endothelial networks. Circ Res 102: 77-85. [PubMed]

55. Zannettino AC, Paton S, Arthur A, Khor F, Itescu S, et al. (2008) Multipotential human adipose-derived stromal stem cells exhibit a perivascular phenotype in vitro and in vivo. J Cell Physiol 214: 413-421. [PubMed]

56. Zografou A, Papadopoulos O, Tsigris C, Kavantzas N, Michalopoulos E, et al. (2013) Autologous transplantation of adipose-derived stem cells enhances skin graft survival and wound healing in diabetic rats. Ann Plast Surg 71: 225-232. [PubMed]

57. Zimmerlin L, Donnenberg VS, Pfeifer ME, Meyer EM, Péault B, et al. (2010) Stromal vascular progenitors in adult human adipose tissue. Cytometry A 77 22-30. [PubMed]

58. Gang EJ, Bosnakovski D, Figueiredo CA, Visser JW, Perlingeiro RC (2007) SSEA-4 identifies mesenchymal stem cells from bone marrow. Blood 109 1743-1751. [PubMed] 
Citation: Zielins ER, Luan A, Tevlin R, Wong VW, Momeni A, et al. (2014) Heterogeneity of Progenitor Cell Populations and their Therapeutic Implications. J Stem Cell Res Ther 4: 254. doi:10.4172/2157-7633.1000254

59. Mihaila SM, Gaharwar AK, Reis RL, Khademhosseini A, Marques AP, et al. (2014) The osteogenic differentiation of SSEA-4 sub-population of human adipose derived stem cells using silicate nanoplatelets. Biomaterials 35: 90879099. [PubMed]

60. Li H, Zimmerlin L, Marra KG, Donnenberg VS, Donnenberg AD, et al. (2011) Adipogenic potential of adipose stem cell subpopulations. Plast Reconstr Surg 128: 663-672. [PubMed]

61. Sowa Y, Imura T, Numajiri T, Takeda K, Mabuchi Y, et al. (2013) Adipose stromal cells contain phenotypically distinct adipogenic progenitors derived from neural crest. PLoS One 8: e84206. [PubMed]

62. Chung MT, Liu C, Hyun JS, Lo DD, Montoro DT, et al. (2013) CD90 (Thy-1)positive selection enhances osteogenic capacity of human adipose-derived stromal cells. Tissue Eng Part A 19: 989-997. [PubMed]

63. McArdle A, Chung MT, Paik KJ, Duldulao C, Chan C, et al. (2014) Positive Selection for Bone Morphogenetic Protein Receptor Type-IB Promotes Differentiation and Specification of Human Adipose-Derived Stromal Cells Toward an Osteogenic Lineage. Tissue Eng Part A 20: 3031-3040. [PubMed]

64. Rada T, Santos TC, Marques AP, Correlo VM, Frias AM, et al. (2012) Osteogenic differentiation of two distinct subpopulations of human adipose-derived stem cells: an in vitro and in vivo study. J Tissue Eng Regen Med 6: 1-11. [PubMed]

65. James AW, Zara JN, Zhang X, Askarinam A, Goyal R, et al. (2012) Perivascular stem cells: a prospectively purified mesenchymal stem cell population for bone tissue engineering. Stem Cells Transl Med 1: 510-519. [PubMed]

66. Rada T, Reis RL, Gomes ME (2011) Distinct stem cells subpopulations isolated from human adipose tissue exhibit different chondrogenic and osteogenic differentiation potential. Stem Cell Rev 7: 64-76. [PubMed]

67. Jo $\mathrm{CH}$, Ahn HJ, Kim HJ, Seong SC, Lee MC (2007) Surface characterization and chondrogenic differentiation of mesenchymal stromal cells derived from synovium. Cytotherapy 9: 316-327. [PubMed]

68. Ishimura D, Yamamoto N, Tajima K, Ohno A, Yamamoto Y, et al. (2008) Differentiation of adipose-derived stromal vascular fraction culture cells into chondrocytes using the method of cell sorting with a mesenchymal stem cell marker. Tohoku J Exp Med 216: 149-156. [PubMed]

69. Jiang T, Liu W, LvX, Sun H, Zhang L, et al. (2010) Potent in vitro chondrogenesis of CD105 enriched human adipose-derived stem cells. Biomaterials 31: 35643571. [PubMed]

70. Anderson P, Carrillo-Gálvez AB, García-Pérez A, Cobo M, Martín F (2013) CD105 (endoglin)-negative murine mesenchymal stromal cells define a new multipotent subpopulation with distinct differentiation and immunomodulatory capacities. PLoS One 8: e76979. [PubMed]

71. Arufe MC, De la Fuente A, Fuentes I, de Toro FJ, Blanco FJ (2010) Chondrogenic potential of subpopulations of cells expressing mesenchymal stem cell markers derived from human synovial membranes. J Cell Biochem 111: 834-845. [PubMed]

72. Campbell DD, Pei M (2012) Surface markers for chondrogenic determination: a highlight of synovium-derived stem cells. Cells 1: 1107-1120. [PubMed]

73. Swart GW (2002) Activated leukocyte cell adhesion molecule (CD166/ALCAM): developmental and mechanistic aspects of cell clustering and cell migration. Eur J Cell Biol 81: 313-321. [PubMed]

74. Hunziker EB, Kapfinger E, Geiss J (2007) The structural architecture of adult mammalian articular cartilage evolves by a synchronized process of tissue resorption and neoformation during postnatal development. Osteoarthritis Cartilage 15: 403-413. [PubMed]

75. Pretzel D, Linss S, Rochler S, Endres M, Kaps C, et al. (2011) Relative percentage and zonal distribution of mesenchymal progenitor cells in human osteoarthritic and normal cartilage. Arthritis Res Ther 13: R64. [PubMed]

76. Diaz-Romero J, Gaillard JP, Grogan SP, Nesic D, Trub T, et al. (2005) Immunophenotypic analysis of human articular chondrocytes: changes in surface markers associated with cell expansion in monolayer culture. J Cell Physiol 202: 731-742. [PubMed]
77. Nagase T, Muneta T, Ju YJ, Hara K, Morito T, et al (2008) Analysis of the chondrogenic potential of human synovial stem cells according to harvest site and culture parameters in knees with medial compartment osteoarthritis. Arthritis Rheum 58: 1389-1398. [PubMed]

78. Gullo F, De Bari C (2013) Prospective purification of a subpopulation of human synovial mesenchymal stem cells with enhanced chondro-osteogenic potency. Rheumatology (Oxford) 52: 1758-1768. [PubMed]

79. Ponticiello MS, Schinagl RM, Kadiyala S, Barry FP (2000) Gelatin-based resorbable sponge as a carrier matrix for human mesenchymal stem cells in cartilage regeneration therapy. J Biomed Mater Res 52: 246-255. [PubMed]

80. Wang Y, Kim UJ, Blasioli DJ, Kim HJ, Kaplan DL (2005) In vitro cartilage tissue engineering with $3 \mathrm{D}$ porous aqueous-derived silk scaffolds and mesenchymal stem cells. Biomaterials 26: 7082-7094. [PubMed]

81. Erickson GR, Gimble JM, Franklin DM, Rice HE, Awad $\mathrm{H}$, et al. (2002) Chondrogenic potential of adipose tissue-derived stromal cells in vitro and in vivo. Biochem Biophys Res Commun 290: 763-769. [PubMed]

82. Dragoo JL, Samimi B, Zhu M, Hame SL, Thomas BJ, et al. (2003) Tissueengineered cartilage and bone using stem cells from human infrapatellar fat pads. J Bone Joint Surg Br 85: 740-747. [PubMed]

83. Tholpady SS, Llull R, Ogle RC, Rubin JP, Futrell JW, et al. (2006) Adipose tissue: stem cells and beyond. Clin Plast Surg 33: 55-62. [PubMed]

84. Dechesne CA, Dani C (2011) Stem cells from human adipose tissue: A new too for pharmacological studies and for clinical applications, in Adipose stem cells and regenerative medicine. Springer, New York.

85. Mizuno H, Zuk PA, Zhu M, Lorenz HP, Benhaim P, et al. (2002) Myogenic differentiation by human processed lipoaspirate cells. Plast Reconstr Surg 109 199-209. [PubMed]

86. Di Rocco G, lachininoto MG, Tritarelli A, Straino S, Zacheo A, et al. (2006) Myogenic potential of adipose-tissue-derived cells. J Cell Sci 119: 2945-2952. [PubMed]

87. Rodriguez AM, Pisani D, Dechesne CA, Turc-Carel C, Kurzenne JY, et al (2005) Transplantation of a multipotent cell population from human adipose tissue induces dystrophin expression in the immunocompetent mdx mouse. $J$ Exp Med 201: 1397-1405. [PubMed]

88. Vieira NM, Brandalise V, Zucconi E, Jazedje T, Secco M, et al. (2008) Human multipotent adipose-derived stem cells restore dystrophin expression of Duchenne skeletal-muscle cells in vitro. Biol Cell 100: 231-241. [PubMed]

89. Bacou F, el Andalousi RB, Daussin PA, Micallef JP, Levin JM, et al. (2004) Transplantation of adipose tissue-derived stromal cells increases mass and functional capacity of damaged skeletal muscle. Cell Transplant 13: 103-111. [PubMed]

90. Kang Y, Park C, Kim D, Seong CM, Kwon K, et al. (2010) Unsorted human adipose tissue-derived stem cells promote angiogenesis and myogenesis in murine ischemic hindlimb model. Microvasc Res 80: 310-316. [PubMed]

91. Lei H, Yu B, Huang Z, Yang X, Liu Z, et al. (2013) Comparative analysis of mesenchymal stem cells from adult mouse adipose, muscle, and fetal muscle. Mol Biol Rep 40: 885-892. [PubMed]

92. Bayati V, Hashemitabar M, Gazor R, Nejatbakhsh R, Bijannejad D (2013) Expression of surface markers and myogenic potential of rat bone marrow- and adipose-derived stem cells: a comparative study. Anat Cell Biol 46: 113-121. [PubMed] 